\title{
Pattern of liver injury in adult patients with COVID-19: a retrospective analysis of 105 patients
}

\author{
Qi Wang ${ }^{1,2}$, Hong Zhao', Li-Gai Liu', Yan-Bin Wang ${ }^{1}$, Ting Zhang ${ }^{1}$, Ming-Hui Li', Yan-Li Xu³, Gui-Ju Gao ${ }^{3}$, \\ Hao-Feng Xiong ${ }^{4}$, Ying Fan' ${ }^{1}$, Ying Cao ${ }^{1}$, Rui Ding ${ }^{1}$, Jing-Jing Wang ${ }^{1}$, Cheng Cheng ${ }^{1}$ and Wen Xie ${ }^{1 *}$
}

\begin{abstract}
Background: Recent studies reported that patients with coronavirus disease-2019 (COVID-19) might have liver injury. However, few data on the combined analysis and change patterns of alanine aminotransferase (ALT), aspartate aminotransferase (AST) and total bilirubin (TBil) have been shown.

Methods: This is a single-center retrospective study. A total of 105 adult patients hospitalized for confirmed COVID19 in Beijing Ditan Hospital between January 12, and March 17, 2020 were included, and divided into mild group $(n=79)$ and severe group $(n=26)$. We compared liver functional test results between the two groups. Category of ALT change during the disease course was also examined.

Results: $56.2 \%$ (59/105) of the patients had unnormal ALT, AST, or total TBil throughout the course of the disease, but in $91.4 \%(96 / 105)$ cases the level of ALT, AST or TBil $\leq 3$ fold of the upper limit of normal reference range (ULN). The overall distribution of ALT, AST, and TBil were all significantly difference between mild and severe group $(P<0.05)$. The percentage of the patients with elevated both ALT and AST was $12.7 \%(10 / 79)$ in mild cases vs. 46.2\% $(12 / 26)$ in severe cases $(P=0.001) .34 .6 \%(9 / 26)$ severe group patients started to have abnormal ALT after admission, and $73.3 \%$ (77/105) of all patients had normal ALT before discharge.

Conclusions: Elevated liver function index is very common in patients with COVID-19 infection, and the level were less than $3 \times U L N$, but most are reversible. The abnormality of 2 or more indexes is low in the patients with COVID19 , but it is more likely to occur in the severe group.
\end{abstract}

Keywords: Coronavirus disease-2019, Liver function, Dynamic change

\section{Background}

Core clinical features in patients with coronavirus disease-2019 (COVID-19) include fever, dry cough and asthenia. Patients with severe illness often experience dyspnea and/or hypoxemia within one week after symptom onset, and the mortality rate is about $1-3 \%$ [1]. Liver biochemical abnormalities have been documented

\footnotetext{
*Correspondence: xiewen6218@163.com

${ }^{1}$ Center of Liver Diseases, Beijing Ditan Hospital, Capital Medical University, Beijing 100,015, China

Full list of author information is available at the end of the article
}

in COVID-19 patients, and typically include mild elevations of alanine aminotransferase (ALT) and aspartate aminotransferase (AST), ranging from 14 to 53\% [1-4]. Patients with severe illness, and particularly those requiring intensive care unit (ICU) admission, tend to have higher rate of transaminase elevation than in those with mild to moderate illness $[4,5]$. No studies have reported the incidence of concurrent elevation of serum transaminases and total bilirubin (TBil) in patients with COVID19. Also, few studies examined the dynamic change of liver function throughout the course of COVID-19. 


\section{Methods}

\section{Study design}

This is a single-center retrospective study. Medical records were screened to identify adult patients receiving treatment for confirmed COVID-19 at Beijing Ditan Hospital, Capital Medical University, from January 12, 2020 to March 17, 2020. The cases were divided into mild group (mild and ordinary type, $n=79$ ) vs. severe group (severe and critical type, $n=26$ ) according to their condition [6]. This study was approved by the Ethics Committee of Beijing Ditan Hospital, Capital Medical University (\#2020-010-01).

\section{Patient selection}

For inclusion in the analysis, patients must be $\geq 18$ years of age. The diagnosis and classification (into mild vs. severe cases) of COVID-19 was based on the "New Coronavirus Pneumonia Diagnosis and Treatment Plan (Trial Edition 4-6)" published by the Chinese Health and Health Council [6]. Mild type was defined as lack of signs for pneumonia based on image results. Ordinary type was defined as having fever and respiratory symptoms radiologic signs of pneumonia. Severe type was defined as the presence of any of the following: respiratory distress (respiratory rate $>30 \mathrm{times} / \mathrm{min}$ ), oxygen saturation $\mathrm{SpO}_{2}$ (resting state) $\leq 93 \%$, abnormal blood gas analysis: partial arterial oxygen pressure $\left(\mathrm{PaO}_{2}\right) /$ fraction of inspired oxygen $\left(\mathrm{FiO}_{2}\right) \leq 300 \mathrm{mmHg}$. Critical type was defined as the presence of any of the following: respiratory failure that requires mechanical ventilation, shock, accompanied by other organ failure that needs ICU admission. COVID-19 was based on PCR for the SARS-
CoV-2 gene using nasal or pharyngeal swabs taken prior to admission. All patients received at least one chest CT scan after admission. The criteria for discharge from hospital included: Normal body temperature for at least 3 days; resolution of respiratory symptoms; chest CT showing improvement in lung inflammation; twonegative RT-PCR results for SARS-CoV2 respiratory samples at least $24 \mathrm{~h}$ apart [6].

Exclusion criteria: 1) Patients who were still hospitalized in Beijing Ditan Hospital, Capital Medical University until March 17, 2020. 2) The patients did not have complete medical history, and in particular, liver function tests were not performed during hospitalization.

\section{Data collection}

The following information was extracted from the medical records: sex, age, alcohol use, time of onset, hospital stay and existing diseases. Standard liver blood chemistry was conducted at admission as well as during hospitalization. Some patients also underwent abdominal ultrasound examination. The normal reference ranges were: 1) ALT: male 9.0-50.0 U/L, female 7.0-40.0 U/L; 2) AST: male 15.0-40.0 U/L, female 13.0-35.0 U/L; 3) TBil: 0$18.8 \mu \mathrm{mol} / \mathrm{L} ; 4)$ albumin (ALB): 40.0-55.0 g/L; 5) cholinesterase (CHE): 4000-11,000 U/L.

\section{Statistical analysis}

All statistical analyses were conducted using SPSS (Version 17.0). Categorical variables were presented as percentages, and continuous variables as means + standard deviations (SD) or medians and inter-quartile ranges

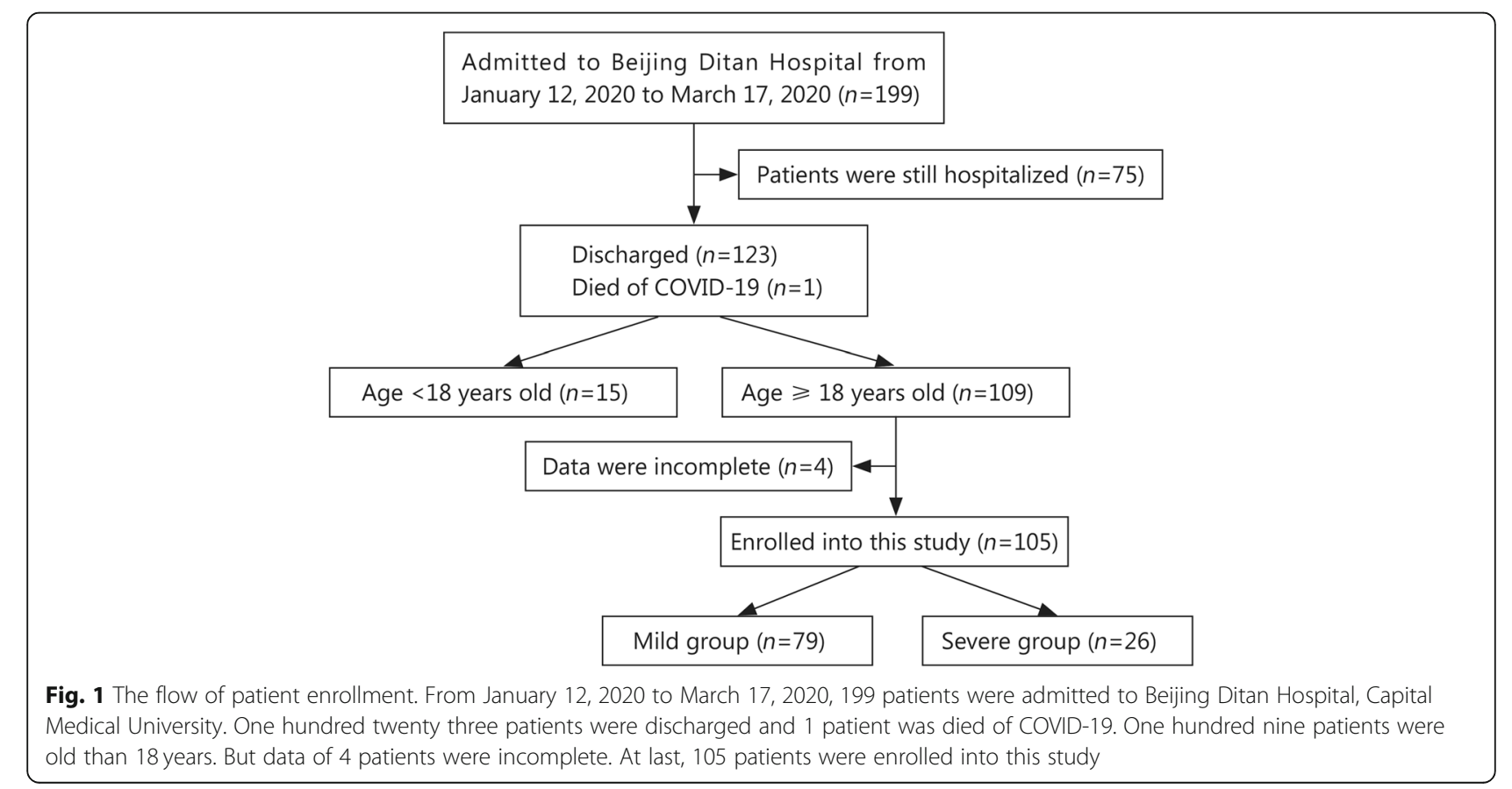


(IQR, 25-75th). Comparisons between groups were made by using chi-square test for mortality or differences in categorical variables and Student's $t$-test or Wilcoxon rank sum test for continuous variables, as appropriate. $P<0.05$ was considered statistically significant.

\section{Results}

\section{Patient selection process}

A total of 105 patients were included in this study, accounting for $52.8 \%$ of the patients receiving treatment for COVID-19 at Beijing Ditan Hospital, Capital Medical University from January 12, 2020 to March 17, 2020. Patient selection for inclusion in the analysis is shown in Fig. 1.

\section{Clinical characteristics at admission}

The results of clinical characteristics at admission are presented in Table 1 . The median age was 45.0 years
(IQR: 33.5, 59.5; range: 18 to 92) in the entire cohort, 41.0 years (IQR: $33.0,56.0)$ in mild cases $(n=79)$ and 59.0 years $(48.5,69.8)$ in severe cases $(n=26)(P<0.001)$. The male-female ratio was 1:1 in mild cases and 2.2:1 in severe cases $(P=0.073)$. The time from symptom onset to hospital admission was 4.0 days in the mild cases vs. 7.0 days in severe cases $(P=0.005)$. The median hospital stay was 22.0 days in the entire cohort, 20.0 days in mild cases vs. 31.5 days in severe cases $(P=0.001)$.

A total of 89 out of 105 patients underwent abdominal ultrasound scans for fatty liver. Fatty liver was detected in $40.0 \%$ of the mild cases vs. $45.8 \%$ in severe cases $(P=$ $0.636)$. One patient had extended history of heavy alcohol use (ethanol consumption at $>40 \mathrm{~g} / \mathrm{d}$ ). All patients denied a history of chronic hepatitis B or chronic hepatitis C. HBsAg, anti-HCV, anti-HIV, and syphilis-specific antibodies were tested in 22 patients; the results showed

Table 1 Clinical characteristic of the patients with COVID-19 at admission

\begin{tabular}{|c|c|c|c|c|}
\hline Item & Overall & Mild group & Severe group & $P$-value \\
\hline Male [n (\%)] & $56 / 105(53.3)$ & $38 / 79(48.1)$ & 18/26 (69.2) & 0.073 \\
\hline Age (year, IQR) & $\begin{array}{l}45.0[33.5,59.5] \\
(n=105)\end{array}$ & $\begin{array}{l}41.0[33.0,56.0] \\
(n=79)\end{array}$ & $\begin{array}{l}59.0[48.5,69.8] \\
(n=26)\end{array}$ & $<0.001$ \\
\hline Disease duration (d, IQR) & $\begin{array}{l}5.0[3.0,8.0] \\
(n=105)\end{array}$ & $\begin{array}{l}4.0[2.0,7.0] \\
(n=79)\end{array}$ & $\begin{array}{l}7.0[5.0,10.25] \\
(n=26)\end{array}$ & 0.005 \\
\hline Hospital stay (d, IQR) & $\begin{array}{l}22.0[17.0,31.5] \\
(n=105)\end{array}$ & $\begin{array}{l}20.0[16.0,28.0] \\
(n=79)\end{array}$ & $\begin{array}{l}31.5[22.5,35.5] \\
(n=26)\end{array}$ & 0.001 \\
\hline Fatty liver by ultrasound [n (\%)] & $37 / 89(41.6)$ & 26/65 (40.0) & $11 / 24(45.8)$ & 0.636 \\
\hline Hypertension [n (\%)] & 15/105 (14.3) & 9/79 (11.4) & 6/26 (23.1) & 0.190 \\
\hline Diabetes [n (\%)] & 6/105 (5.7) & 3/79 (3.8) & $3 / 26(11.5)$ & 0.160 \\
\hline HBsAg (+) [n (\%)] & $0 / 22(0)$ & $0 / 14(0)$ & 0/8 (0) & - \\
\hline Anti-HCV (+) [n (\%)] & $1 / 22(0)$ & 0/14 (0) & $1 / 8(12.5)$ & 0.364 \\
\hline Heavy alcohol use [n (\%)] & 1/105 (1.0) & $1 / 79(1.3)$ & $0 / 26(0)$ & 1.000 \\
\hline $\operatorname{ALT}(U / L, I Q R)$ & $\begin{array}{l}23.5[14.0,36.0] \\
(n=105)\end{array}$ & $\begin{array}{l}22.0[14.0,34.5] \\
(n=79)\end{array}$ & $\begin{array}{l}27.8[18.8,38.0] \\
(n=26)\end{array}$ & 0.088 \\
\hline$<1 \times \operatorname{ULN}[n(\%)]$ & $88(83.8)$ & $67(84.8)$ & $21(80.8)$ & 0.482 \\
\hline $1-2 \times \operatorname{ULN}[n(\%)]$ & $13(12.4)$ & $10(12.7)$ & $3(11.5)$ & \\
\hline$\geq 2 \times \operatorname{ULN}[\mathrm{n}(\%)]$ & $4(3.8)$ & $2(2.5)$ & $2(7.7)$ & \\
\hline AST (U/L, IQR) & $\begin{array}{l}24.2[19.7,34.8] \\
(n=50)\end{array}$ & $\begin{array}{l}22.0[18.4,31.7] \\
(n=39)\end{array}$ & $46.3[25.5,54.3](n=11)$ & $<0.001$ \\
\hline$<1 \times \operatorname{ULN}[n(\%)]$ & $41(82.0)$ & $37(94.9)$ & $4(36.4)$ & $<0.001$ \\
\hline $1-2 \times \operatorname{ULN}[\mathrm{n}(\%)]$ & $8(16.0)$ & $2(5.1)$ & $6(54.5)$ & \\
\hline$\geq 2 \times \operatorname{ULN}[\mathrm{n}(\%)]$ & $1(2.0)$ & $0(0)$ & $1(9.1)$ & \\
\hline TBil (umol/L, IQR) & $\begin{array}{l}10.2[7.4,12.9] \\
(n=50)\end{array}$ & $\begin{array}{l}10.0[7.1,12.9] \\
(n=39)\end{array}$ & $10.6[8.3,12.9](n=11)$ & 0.535 \\
\hline$<1 \times \operatorname{ULN}[\mathrm{n}(\%)]$ & $48(96.0)$ & $38(97.4)$ & $10(90.9)$ & 0.395 \\
\hline $1-2 \times \operatorname{ULN}[n(\%)]$ & $2(4.0)$ & $1(2.6)$ & $1(9.1)$ & \\
\hline$\geq 2 \times$ ULN [n (\%)] & $0(0)$ & $0(0)$ & $0(0)$ & \\
\hline CHE (U/L, IQR) & $7490[6801,9527](n=50)$ & $6517[6843,9682](n=39)$ & $6972[4893,8459](n=11)$ & 0.137 \\
\hline ALB (g/L, IQR) & $\begin{array}{l}41.6[37.9,44.7] \\
(n=49)\end{array}$ & $\begin{array}{l}42.0[38.7,45.5] \\
(n=39)\end{array}$ & $37.2[34.2,41.8](n=10)$ & 0.012 \\
\hline
\end{tabular}


positive anti-HCV but no HCV RNA in one patient. Among the 37 patients with fatty liver, 11 (29.7\%) had elevated ALT; 6 (21.6\%) were mild cases and 5 (13.5\%) were severe cases. In 9 out of the 11 cases, ALT elevation was $<2 \times \mathrm{ULN}$ (upper limit of normal reference range); the highest ALT level was $129.9 \mathrm{U} / \mathrm{L}$. We did not perform statistical analysis due to the small sample size.

The analysis results of liver functions at admission are also presented in Table 1. Seventeen out of 105 patients (16.2\%) elevated ALT. The median ALT level was 22.0 $\mathrm{U} / \mathrm{L}$ in mild cases vs. $27.8 \mathrm{U} / \mathrm{L}$ in severe cases $(P=$ $0.088)$. However, there was no difference in the distribution of ALT at different levels between the two groups $(P=0.482)$. The highest ALT was $357.0 \mathrm{U} / \mathrm{L}$, which was appeared on a male mild group patient. AST, TBil, CHE, and ALB levels were available in 50 patients only. The median AST was $22.0 \mathrm{U} / \mathrm{L}$ in mild cases vs. $46.3 \mathrm{U} / \mathrm{L}$ in severe cases $(P<0.001)$. The rate of isolated AST elevation was higher at $63.6 \%$ in severe cases vs. $5.1 \%$ in mild cases $(\mathrm{P}<0.001)$. AST was elevated at $\geq 2 \times \mathrm{ULN}$ in one severe cases. The median TBil was $10.0 \mu \mathrm{mol} / \mathrm{L}$ in mild cases vs. $10.6 \mu \mathrm{mol} / \mathrm{L}$ in severe cases $(p=0.535)$. Among the 50 patients with TBil, only 2 cases had elevated TBil (one patient in every group, and both below $2 \times \mathrm{ULN}$ ). CHE analysis did not show statistically significant difference between the two groups $(p=0.137)$. A total of 22 (30.0\%) patients had elevated ALT or AST or TBil, including 14 (17.7\%) mild cases and 8(30.8\%) severe cases $(P=0.156)$. The median ALB was $42.0 \mathrm{~g} / \mathrm{L}$ in mild cases vs. $37.2 \mathrm{~g} / \mathrm{L}$ in severe cases $(P=0.012)$.

\section{Analysis of liver function during hospitalization}

We compared the differences of the overall distribution and the abnormal rates of liver function indexes at different cut-off values as 1,2 , or $3 \times \mathrm{ULN}$, respectively, between the two groups (see Table 2 and Fig. 2). One critically ill patient died within the study period. A total of 508 ALT measurements, 383 AST measurements, and 383 TBil measurements during hospitalization were available for analysis. The highest was $357.0 \mathrm{U} / \mathrm{L}$ for ALT, 156.3 U/L for AST, and $102.9 \mu \mathrm{mol} / \mathrm{L}$ for TBil. It was showed that the overall distribution of ALT, AST, and TBil were all significantly difference between mild and severe group $(P<0.05)$.

In the single index analysis, the percentage of the patients having only one abnormal index was $56.2 \%$ in the entire cohort, $51.9 \%$ in mild cases vs. $69.2 \%$ in severe cases $(P=0.122)$. Nineteen $(18.1 \%)$ patients had elevated ALT, AST or TBil levels $\geq 2 \times$ ULN: 10 in severe cases and 9 in mild cases $(P=0.004)$.

In the combined analysis, ALT or AST associated with TBil and elevation of all 3 indices were more common in severe cases $(P<0.001$ or $P=0.001)$. The proportion of elevated TBil with elevated AST was 9.3\%, and TBil
Table 2 Liver function of the patients with COVID-19 during hospitalization [n (\%)].

\begin{tabular}{|c|c|c|c|c|}
\hline Item & Overall & Mild group & Severe group & P-value \\
\hline$\overline{A L T}$ & $(n=105)$ & $(n=79)$ & $(n=26)$ & 0.026 \\
\hline$<1 \times$ ULN & 65 (61.9) & $54(68.4)$ & $11(42.3)$ & \\
\hline $1-2 \times U L N$ & $25(23.8)$ & $17(21.5)$ & $8(30.8)$ & \\
\hline $2-3 \times U L N$ & $8(7.6)$ & $3(3.8)$ & $5(19.2)$ & \\
\hline$\geq 3 \times$ ULN & $7(6.7)$ & $5(6.3)$ & $2(7.7)$ & \\
\hline AST & $(n=97)$ & $(n=72)$ & $(n=25)$ & 0.001 \\
\hline$<1 \times$ ULN & $64(66.0)$ & $55(76.4)$ & $9(36.0)$ & \\
\hline $1-2 \times$ ULN & $24(24.7)$ & $13(18.1)$ & $11(44.0)$ & \\
\hline $2-3 \times$ ULN & $7(7.2)$ & $3(4.2)$ & $4(16.0)$ & \\
\hline$\geq 3 \times$ ULN & $2(2.1)$ & $1(1.4)$ & $1(4.0)$ & \\
\hline TBil & $(n=97)$ & $(n=72)$ & $(n=25)$ & 0.010 \\
\hline$<1 \times U L N$ & $73(75.3)$ & $57(79.2)$ & $16(64.0)$ & \\
\hline $1-2 \times$ ULN & $20(20.6)$ & $15(20.8)$ & $5(20.0)$ & \\
\hline $2-3 \times U L N$ & $2(2.1)$ & $0(0)$ & $2(8.0)$ & \\
\hline$\geq 3 \times$ ULN & $2(2.1)$ & $0(0)$ & $2(8.0)$ & \\
\hline$A L T+A S T$ & $(n=105)$ & $(n=79)$ & $(n=26)$ & 0.001 \\
\hline$<1 \times$ ULN & $83(79.0)$ & $69(87.3)$ & $14(53.8)$ & \\
\hline $1-2 \times U L N$ & $17(16.2)$ & $8(10.1)$ & $9(34.6)$ & \\
\hline $2-3 \times$ ULN & $3(2.9)$ & $2(2.5)$ & $1(3.9)$ & \\
\hline$\geq 3 \times$ ULN & $2(1.9)$ & $0(0)$ & $2(7.7)$ & \\
\hline$A L T+T_{B i l}{ }^{a}$ & $(n=105)$ & $(n=79)$ & $(n=26)$ & 0.001 \\
\hline$<1 \times$ ULN & 96 (91.4) & 77 (97.5) & $19(73.1)$ & \\
\hline $1-2 \times$ ULN & $8(7.6)$ & $2(2.5)$ & $6(23.1)$ & \\
\hline $2-3 \times$ ULN & $1(1.0)$ & $0(0)$ & $1(3.8)$ & \\
\hline$A S T+$ TBil $^{a}$ & $(n=97)$ & $(n=72)$ & $(n=25)$ & $<0.001$ \\
\hline$<1 \times U L N$ & $88(90.7)$ & 71 (98.6) & $17(68.0)$ & \\
\hline $1-2 \times$ ULN & $7(7.2)$ & $1(1.4)$ & $6(24.0)$ & \\
\hline $2-3 \times$ ULN & $2(2.1)$ & $0(0)$ & $2(8.0)$ & \\
\hline$A L T+A S T+T_{B i l}^{a}$ & $(n=105)$ & $(n=79)$ & $(n=26)$ & $<0.001$ \\
\hline$<1 \times$ ULN & $97(92.4)$ & 78 (98.7) & $19(73.1)$ & \\
\hline $1-2 \times U L N$ & $7(6.7)$ & $1(1.3)$ & $6(23.1)$ & \\
\hline $2-3 \times$ ULN & $1(1.0)$ & $0(0)$ & $1(3.8)$ & \\
\hline ALT/AST/TBil & $(n=105)$ & $(n=79)$ & $(n=26)$ & 0.017 \\
\hline$<1 \times$ ULN & $46(43.8)$ & $38(48.1)$ & $8(30.8)$ & \\
\hline $1-2 \times$ ULN & $40(38.1)$ & $32(40.5)$ & $8(30.8)$ & \\
\hline $2-3 \times U L N$ & $10(9.5)$ & $4(5.1)$ & $6(23.1)$ & \\
\hline$\geq 3 \times$ ULN & $9(8.6)$ & $5(6.3)$ & $4(15.4)$ & \\
\hline
\end{tabular}

ALT alanine aminotransferase, AST aspartate aminotransferase, TBil total bilirubin

${ }^{a}$ : In this category, the number of cases that meet the index level $>3 \times$ ULN is 0

with ALT was $8.6 \%(P=1.000)$. A total of 8 patients had elevation in all 3 indices: seven in severe cases vs. only one in mild cases. One patient (in the severe group) had elevation of all 3 indices $\geq 2 \times U L N$. The percentage of 

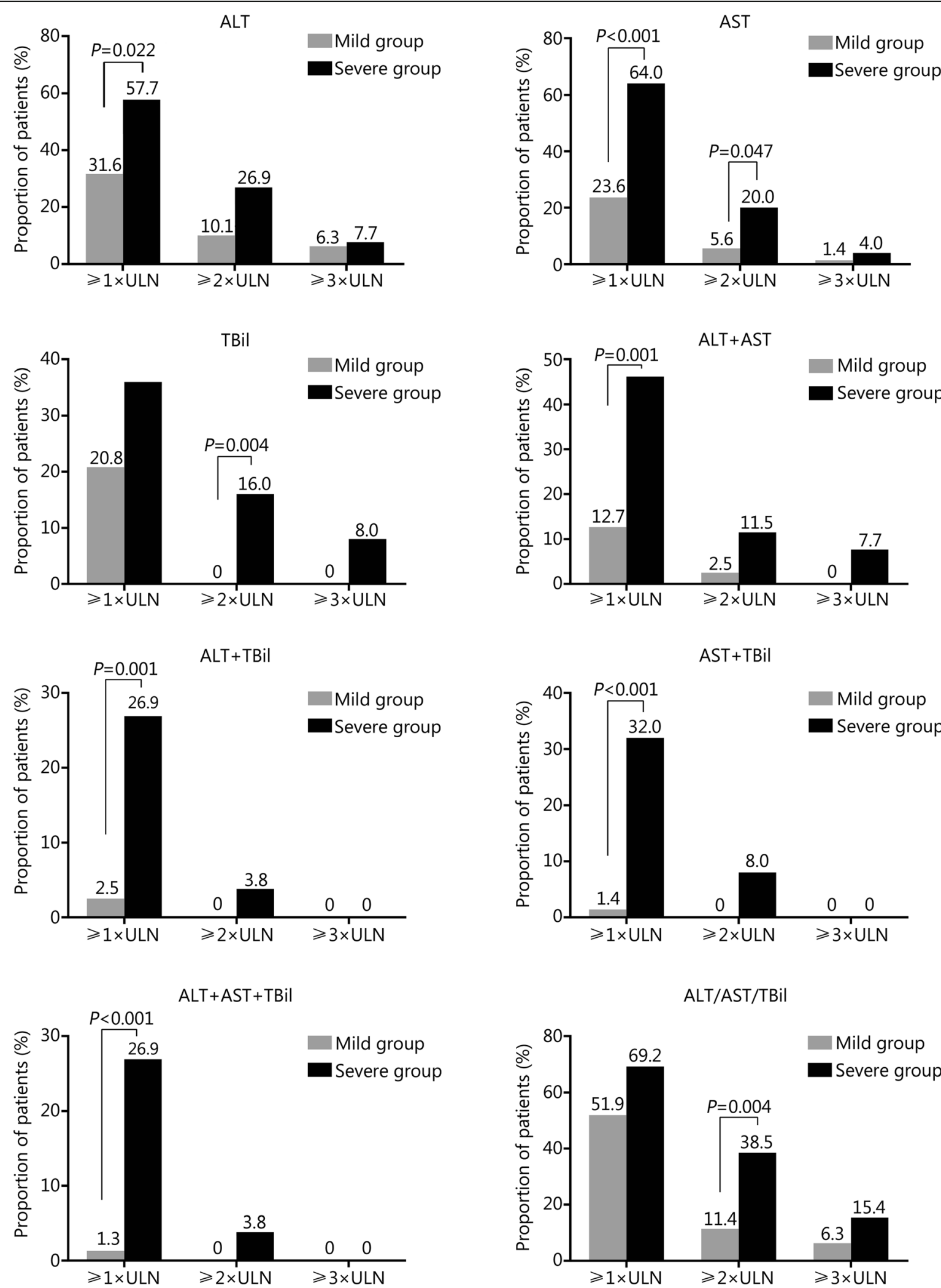

Fig. 2 (See legend on next page.)

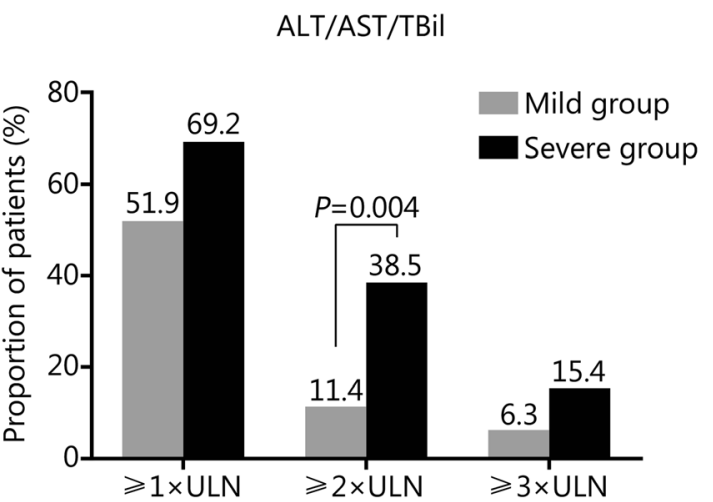


(See figure on previous page.)

Fig. 2 Single or combination analysis of indexes during hospitalization in mild vs. severe cases using different cut-off values. Using the cut-off value as 1,2 , or $3 \times U L N$, respectively, the differences of the overall distribution and the abnormal rates of liver function indexes between the two groups were analyzed. Most of the elevated liver function index were less than $3 \times \mathrm{ULN}$. The abnormality of 2 or more indexes is low in the patients with COVID-19, but it is more likely to occur in the severe group

the patients with elevated both ALT and AST was $12.6 \%$ $(10 / 79)$ in mild cases vs. $46.2 \%(12 / 26)$ in severe cases $(P=0.001)$. Nine patients $(8.6 \%)$ had $\geq 3 \times$ ULN elevation of ALT, AST or TBil.

\section{Categories analysis}

Cases were divided into 4 categories based on ALT at admission and during hospitalization: Normal during the entire period, normal and then abnormal, abnormal and then normal, and abnormal during the entire period. The results are shown in Table 3. Overall, liver functions returned to normal range in 77 (73.3\%) patients before discharge.

A total of 68 patients $(64.8 \%, 68 / 105)$ had normal ALT during the entire period: $12(46.2 \%, 12 / 26)$ in severe cases and $56(70.9 \%, 56 / 79)$ in mild cases $(P=0.032)$.

Twenty $(19.0 \%, 20 / 105)$ patients had normal ALT at admission but had elevated ALT during hospitalization: $9(34.6 \%, 9 / 26)$ in severe cases and $11(13.9 \%, 11 / 79)$ in mild cases $(P=0.007)$. Upon discharge from the hospital, ALT was still elevated in 10 mild cases ( 3 at $>2 \times$ ULN) and in 2 severe cases ( 1 at $>2 \times$ ULN, and 1 was died). Most of ALT elevation occurred between day 4 and day 17 of hospitalization, with a mean of $7.3 \pm 3.0 \mathrm{~d}$ in severe cases vs. $10.7 \pm 4.1 \mathrm{~d}$ in mild cases $(P=0.048)$. Excluding 1 patient with delayed detection for personal reasons, ALT assessment was conducted every $3.0 \pm 0.9 \mathrm{~d}$ between admission and the onset of ALT elevations in mild cases vs. $2.1 \pm 0.6 \mathrm{~d}$ in severe cases $(P=0.015)$.

ALT was elevated at admission but normalized during hospitalization in $9(8.6 \%, 9 / 105)$ patients; 7 patients $(8.9 \%, 7 / 79)$ in mild cases and 2 patients $(7.7 \%, 2 / 26)$ in severe cases $(P=1.000)$. ALT was elevated at admission and remained elevated during hospitalization in $8(7.6 \%$, 8/105) patients: $5(6.3 \%, 5 / 79)$ in mild cases and 3

Table 3 ALT level change during hospitalization in patients with COVID-19 [n (\%)]

\begin{tabular}{lllll}
\hline Category & $\begin{array}{l}\text { Overall } \\
(n=105)\end{array}$ & $\begin{array}{l}\text { Mild group } \\
(n=79)\end{array}$ & $\begin{array}{l}\text { Severe group } \\
(n=26)\end{array}$ & P-value \\
\hline $\begin{array}{l}\text { Normal during the } \\
\text { entire period }\end{array}$ & $68(64.8)$ & $56(70.9)$ & $12(46.2)$ & 0.032 \\
$\begin{array}{l}\text { Normal and then } \\
\text { abnormal }\end{array}$ & $20(19.0)$ & $11(13.9)$ & $9(34.6)$ & 0.007 \\
$\begin{array}{l}\text { Abnormal and then } \\
\text { normal }\end{array}$ & $9(8.6)$ & $7(8.9)$ & $2(7.7)$ & 1.000 \\
$\begin{array}{l}\text { Abnormal during the } \\
\text { entire period }\end{array}$ & $8(7.6)$ & $5(6.3)$ & $3(11.5)$ & 0.406 \\
\hline
\end{tabular}

$(11.5 \%, 3 / 26)$ in severe cases $(P=0.406)$. ALT in the last test remained elevated in 5 patients.

\section{Dynamic ALT change in a representative case with mild illness}

A 45-year-old man has ALT > $7 \times$ ULN (357.0 U/L) upon admission. He presented with cough, fever, and chills on January 24, 2020 and was admitted to the hospital on January 28, 2020 with a diagnosis of COVID-19. He denied heavy alcohol use and chronic liver disease. Abdominal ultrasound showed no fatty liver, and HBsAg and anti-HCV were negative. Treatments included antipyretic, nutritional support, recombinant human interferon $\alpha-2 b$, lopinavir ritonavir tablet, reduced glutathione and compound glycyrrhizin. During the treatment, ALT gradually returned to normal (Fig. 3). After 2 consecutive negative test for SARS-CoV-2 (on February 10, 2020 and February 12, 2020), he was discharged.

\section{Discussion}

Consistent with the previous reports [2], patients with severe illness in the current study had older age, longer duration from disease onset to hospital admission, and higher rate of men was larger. Fatty liver was detected in $40.0 \%(26 / 65)$ of mild cases and $45.8 \%(11 / 24)$ of severe cases. Such a rate is comparable to that in the general population [7], suggesting that fatty liver is not a possible predisposing factor for liver injury in COVID-19 patients.

Liver biochemistry abnormality in COVID-19 patients could be attributed to a variety of factors, including direct hepatocyte injury by the virus [8], drug-induced liver injury [1,9], hypoxic-ischemic microcirculation disorder, and underlying liver diseases. Temporal relationship is an important clue in the identification of direct injury vs. drug-induced liver injury, whereas hepatic injury associated with hypoxic-ischemic microcirculation disorder may be more common in critically ill patients. In the current study, $21.6 \%$ of the abnormal test occurred after hospital admission. AST is widely distributed in muscle, cardiac myocytes and mitochondria. As a result, AST alone is a poor indicator of liver injury. The percentage of patients with elevated ALT or TBil was < $20.0 \%$ at admission, but in severe cases the rate of elevated AST was $63.6 \%$. During hospitalization, the percentage of the patients with elevated ALT, AST as well as TBil in severe cases was $26.9 \%$, which was significantly higher than $1.3 \%$ that in mild cases. Consistent 


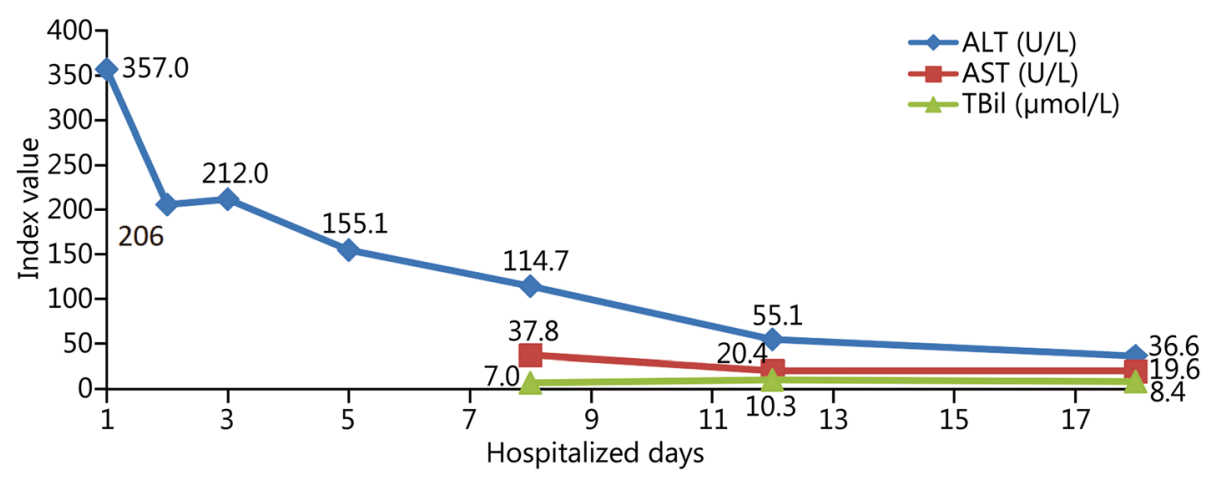

Fig. 3 Dynamics of liver function indexes in 1 mild type patient with ALT elevation. A 45-year-old man has ALT > 7× ULN (357.0 U/L) upon admission. He was admitted to the hospital on January 28, 2020 with a diagnosis of COVID-19. During the treatment, ALT gradually returned to normal. After 2 consecutive negative test for SARS-CoV-2 (on February 10, 2020 and February 12, 2020), he was discharged

with exudative lesions in the lungs, poor nutritional intake after onset in COVID-19 patients, albumin reduction was more pronounced in severe cases than in mild cases. Whether liver injury contributed to albumin change remains unknown.

Further analysis showed that $56.2 \%$ of the patients had elevated ALT, AST, or TBil levels during the course of COVID-19, which was higher than the rate at admission. The percentage of elevated TBil during hospitalization was $20.8 \%$ in mild cases and $36.0 \%$ in severe cases; both were higher than previously reported (9.8 and 20.8\%) [1], and we speculate that the reason for this phenomenon might be related to the higher proportion of severe group patients in this study. One patient had ALT as high as $7590 \mathrm{U} / \mathrm{L}$ in previous report without clear course [2], but the highest ALT in this study was only $357.0 \mathrm{U} / \mathrm{L}$. The percentage of the patients with elevated ALT, AST as well as TBil was 7.6\% in the current study. Only 1 patient who was critically ill had all 3 indices at $\geq 2 \times$ ULN. These findings suggest that liver damage is common but generally mild in COVID-19 patients.

A pattern analysis of ALT change during the study period showed that majority (68 out of 105) of the patients had normal ALT during the entire course of disease. Eight patients had elevated ALT throughout the study period. Considering the mechanism of COVID-19 liver injury, we speculate that these patients might need additional relevant testing to identify underlying causes for liver biochemistry abnormality. Most of patients had ALT elevations between days 4 and 17 of hospitalization, with a mean of $7.3 \mathrm{~d}$ in severe cases and $10.7 \mathrm{~d}$ in mild cases. Since there was difference in testing frequency between the two groups, the difference $(7.3 \mathrm{~d}$ vs. $10.7 \mathrm{~d})$ could be partly reasonably attributed to a difference in disease severity. This finding is consistent with the notion that COVID-19 tend be mild in early stages, but worsens typically in one week [1]. ALT abnormalities in these patients require further exploration, such as druginduced liver injury [9] or associated with changes of disease status.

This study had some limitations. First, it is a retrospective analysis of the data collected from a single center. Second, it has been postulated that novel coronaviruses can enter bile duct epithelial cells through angiotensin-converting enzyme 2 (ACE2) receptors to cause liver injury [10], but alkaline phosphatase (ALP) and $\gamma$-glutamyltransferase (GGT) have not been found to be elevated [11]. We did not assess ALP and GGT in the current study. Medication history in many patients was unknown. Last but not least, the impact of comorbidities (i.e., hypertension, coronary heart disease, type 2 diabetes mellitus, hypothyroidism and chronic obstructive pulmonary disease) was not investigated.

\section{Conclusions}

A significant proportion of patients with COVID-19 maintained normal liver function throughout the course of their disease, but patients with severe illness were more likely to have abnormal liver function. Some patients started to have abnormal liver function parameters during treatment after admission, but most patients had mild and isolated elevations in ALT, AST, or TBil. Most of the patients discharged with normal liver function, and further identification of the aetiology is required for those who did not recover.

\section{Abbreviations}

ACE2: Angiotensin-converting enzyme 2; ALT: Alanine aminotransferase; AST: Aspartate aminotransferase; GGT: y-glutamyltransferase.; TBil: Total bilirubin; ICU: Intensive Care Unit; $\mathrm{PaO}_{2}$ : Partial arterial oxygen pressure; $\mathrm{FiO}_{2}$ : Fraction of inspired oxygen; ALB: Albumin; CHE: Cholinesterase; ALP: Alkaline phosphatase

\section{Acknowledgments}

I thank Dr. Sangeetha Ravi Kumar and Dr. Xiao-Hui Zhang (Loma Linda University Health, School of Medicine, USA) for their review of the article. 


\section{Authors' contributions}

WX and QW conceived and designed the study; HZ, LGL, YBW, TZ, MHL, YLX, GJG, HFX, YF, YC, RD, JJW and CC had roles in clinical management, patient recruitment, formulated the treatment regimens; $\mathrm{OW}, \mathrm{HZ}$ and LGL contributed to data collections and data entry. QW performed the statistics QW and WX also wrote the manuscript. All authors reviewed and approved the final version of the manuscript.

\section{Funding}

This project was supported by Scientific Research Projects of Beijing Ditan Hospital, Capital Medical University, and Projects from Beijing Municipal Science and Technology Commission (D171100003117005), Digestive Medical Coordinated Development Center of Beijing Hospitals Authority (XXZ0402).

\section{Availability of data and materials}

The datasets used and/or analyzed during the current study are available from the corresponding author on reasonable request.

\section{Ethics approval and consent to participate}

This study has been approved by the Ethics Committee of Beijing Ditan Hospital Capital Medical University (number: 2020-010-01).

\section{Consent for publication}

Not applicable.

\section{Competing interests}

The authors declare that they have no competing interests.

\section{Author details}

'Center of Liver Diseases, Beijing Ditan Hospital, Capital Medical University, Beijing 100,015, China. ${ }^{2}$ Beijing Key Laboratory of Emerging Infectious Diseases, Beijing 100,015, China. ${ }^{3}$ Clinical and Research Center of Infectious Diseases, Beijing Ditan Hospital, Capital Medical University, Beijing 100,015, China. ${ }^{4}$ Department of Critical Care Medicine, Beijing Ditan Hospital, Capital Medical University, Beijing 100,015, China.

Received: 6 April 2020 Accepted: 13 May 2020

Published online: 07 June 2020

\section{References}

1. Guan WJ, Ni ZY, Hu Y, Liang WH, Ou CQ, He JX, et al. Clinical Characteristics of Coronavirus Disease 2019 in China. N Engl J Med. 2020. https://doi.org/ 10.1056/NEJMc2009226 [Epub ahead of print].

2. Chen N, Zhou M, Dong X, Qu J, Gong F, Han Y, et al. Epidemiological and clinical characteristics of 99 cases of 2019 novel coronavirus pneumonia in Wuhan, China: a descriptive study. Lancet. 2020:395:507-13.

3. Huang C, Wang Y, Li X, Ren L, Zhao J, Hu Y, et al. Clinical features of patients infected with 2019 novel coronavirus in Wuhan, China. Lancet. 2020;395:497-506

4. Wang D, Hu B, Hu C, Zhu FF, Liu X, Zhang J, et al. Clinical Characteristics of 138 Hospitalized Patients With 2019 Novel Coronavirus-Infected Pneumonia in Wuhan, China. JAMA. 2020. doi: https://doi.org/10.1001/jama.2020.15851585. [Epub ahead of print].

5. Shi HS, Han XY, Jiang NC, Cao YK, AlwalidO GJG, et al. Radiological findings from 81 patients with COVID-19 pneumonia in Wuhan, China: A descriptive study. Lancet Infect Dis. 2020. https://doi.org/10.1016/S1473-3099(20)300864 [Epub ahead of print].

6. National Health Commission of the People's Republic of China. Guidelines for The Diagnosis and Treatment of Novel Coronavirus (2019- nCoV) Infection by The National Health Commission (trial version 6)(2020-0307)[EB/OL].http://www.nhc.gov.cn/xcs/zhengcwj/202003/64856d5b0458141 fa9f376853224d41d7.shtml.

7. Yan J, Xie W, Ou WN, Zhao H, Wang SY, Wang JH, et al. Epidemiological survey and risk factor analysis of fatty liver disease of adult residents, Beijing, China. J Gastroenterol Hepatol. 2013;28:1654-9.

8. Guan GW, Gao L, Wang JW, Wen XJ, Mao TH, Peng SW, et al. Exploring the mechanism of liver enzyme abnormalities in patients with novel coronavirus-infected pneumonia. Zhonghua Gan Zang Bing Za Zhi. 2020; 28(2):100-6
9. Xu Z, Shi L, Wang Y, Zhang J, Huang L, Zhang C, et al. Pathological findings of COVID-19 associated with acute respiratory distress syndrome. Lancet Respir Med. 2020;8(4):420-2.

10. Zhao Y, Zhao Z, Wang Y, et al. Single-cell RNA expression profiling of ACE2, the putative receptor of Wuhan 2019-nCov. BioRxiv. 2020. https://doi.org/10. 1101/2020.02.11.20022228 [Epub ahead of print].

11. Yao N, Wang SN, Lian JQ, Sun YT, Zhang GF, Kang WZ, et al. Clinical characteristics and influencing factors of patients with novel coronavirus pneumonia combined with liver injury in Shaanxi region. Zhonghua Gan Zang Bing Za Zhi. 2020;28(3):234-9.

\section{Ready to submit your research? Choose BMC and benefit from:}

- fast, convenient online submission

- thorough peer review by experienced researchers in your field

- rapid publication on acceptance

- support for research data, including large and complex data types

- gold Open Access which fosters wider collaboration and increased citations

- maximum visibility for your research: over $100 \mathrm{M}$ website views per year

At BMC, research is always in progress.

Learn more biomedcentral.com/submissions 